\title{
Fracture resistance of monolithic zirconia molar crowns with reduced thickness
}

KEISUKE NAKAMURA ${ }^{1,2}$, AKIO HARADA ${ }^{3}$, RYOICHI INAGAKI ${ }^{4}$, TARO

KANNO $^{3}$, YOSHIMI NIWANO $^{2}$, PERCY MILLEDING ${ }^{1} \&$ ULF ÖRTENGREN $^{1,5}$

Running title: Monolithic zirconia molar crowns

1. Department of Prosthetic Dentistry/Dental Materials Science, Institute of Odontology, University of Gothenburg, Gothenburg, Sweden

2. Laboratory for Redox Regulation, Tohoku University Graduate School of Dentistry, Sendai, Japan

3. Division of Molecular and Regenerative Prosthodontics, Tohoku University Graduate School of Dentistry, Sendai, Japan

4. Tohoku University School of Dental Laboratory Technicians, Sendai, Japan

5. Department of Clinical Dentistry/Faculty of Health Sciences, The Arctic University of Norway, Tromsø, Norway

\section{Corresponding author}

Keisuke Nakamura

Laboratory for Redox Regulation, Tohoku University Graduate School of Dentistry

4-1 Seiryo, Aoba-ku, Sendai 980-8575, Japan

Phone: +81-22-795-3976, Fax: +81-22-795-4110

E-mail: keisuke@m.tohoku.ac.jp

Number of Tables: 2

Number of Figures: 4 


\section{Abstract}

Objectives. The purpose of the present study was to analyze the relationship between fracture load of monolithic zirconia crowns and axial/occlusal thickness, and to evaluate the fracture resistance of monolithic zirconia crowns with reduced thickness in comparison with that of monolithic lithium disilicate crowns with regular thickness.

Materials and methods. Monolithic zirconia crowns (Lava Plus Zirconia, 3M/ESPE) with specified axial/occlusal thicknesses and lithium disilicate crowns (IPS e.max press, Ivoclar/Vivadent) with regular thickness were fabricated using a dental CAD/CAM system and a press technique, respectively. The crowns cemented onto dies were loaded until fracture. Based on measurements of the crown thickness made by micro-CT and the fracture load, multiple regression analysis was performed. Results. It was revealed that the occlusal thickness significantly affected the fracture load $(p<0.01)$ but the axial thickness did not $(\mathrm{p}=0.2828)$. Although the reduction of the occlusal thickness decreased the fracture resistance of the monolithic zirconia crowns, the fracture load of the zirconia crowns with the occlusal thickness of $0.5 \mathrm{~mm}(5558 \pm 522 \mathrm{~N})$ was significantly higher than that of lithium disilicate crowns with an occlusal thickness of $1.5 \mathrm{~mm}(3147 \pm 409 \mathrm{~N})$. Conclusion. Within the limitations of the present study, it was suggested that monolithic zirconia crown with chamfer width of $0.5 \mathrm{~mm}$ and occlusal thickness of $0.5 \mathrm{~mm}$ can be used in the molar region in terms of fracture resistance.

Key words: computer-aided design, lithium disilicate, X-Ray microtomography, zirconium oxide 


\section{Introduction}

Zirconia has increasingly been used in dentistry over the recent years, taking advantage of its high strength [1]. The strength is due to the crystalline phase transformation system of zirconia (i.e. stress-induced transformation toughening) giving the material high mechanical strength and reliability [2]. In addition, the development of computer aided designing (CAD)/computer aided manufacturing (CAM) technology has increased the use. Thus, all-ceramic crowns and fixed dental prostheses (FDPs) utilizing zirconia as a framework have been provided to patients with sufficient strength and a good esthetic outcome $[3,4]$.

Due to the original color of zirconia (i.e. bright white), its application has been limited. The development of translucent tooth-colored zirconia, however, enables fabrication of restorations without veneering porcelain (i.e. monolithic zirconia crown) [5, 6]. Advantages of monolithic zirconia crowns may be limited amounts of defects due to fabrication with $\mathrm{CAD} / \mathrm{CAM}$ technique and reduced production time/cost.

When a tooth is restored with a conventional all-ceramic crown, irrespective of the materials used, it is recommended that axial and occlusal reduction of the preparation should be 1.5 and $2.0 \mathrm{~mm}$, respectively [7]. The reason is to obtain sufficient strength of the reconstruction and space for veneering [7]. It has been demonstrated that monolithic lithium disilicate crowns for posterior teeth with reduced occlusal thickness showed more fatigue failures than those with a thickness of $\geq 1.5$ $\mathrm{mm}[8]$. Since zirconia has higher flexural strength (>1000 MPa) $[9,10]$ than lithium disilicate (about $400 \mathrm{MPa}$ ) [11, 12], the fracture resistance of monolithic zirconia crowns may be acceptable even at a reduced thickness. Still, to the knowledge of the 
authors, there are few data in the matter available.

Therefore, the purpose of this study was 1) to analyze the relationship between fracture load of monolithic zirconia crowns and axial/occlusal thickness, and 2) to evaluate the fracture resistance of monolithic zirconia crowns with reduced thickness in comparison with that of monolithic lithium disilicate crowns with regular thickness. The hypothesis was that the fracture resistance of monolithic zirconia crowns with reduced thickness should still be sufficient for use in the molar region.

\section{Materials and methods}

Preparation of dies

Plastic models of tooth 46 (A5A-500, NISSIN, Kyoto, Japan) were used to prepare different types of abutments. The tooth model was prepared with a chamfer finish line $(0.5,0.7$ and $1.0 \mathrm{~mm})$ (Fig. 1a). The total occlusal convergence angle was finally finished using a milling machine (F3 ergo, DeguDent GmbH, Hanau-Wolfgang, Germany) to be $10^{\circ}$ (Fig. 1a). The prepared tooth models were scanned using a digital scanner (LavaScan ST, 3M/ESPE, St. Paul, MN, USA) made for a dental CAD/CAM system (Lava System, 3M/ESPE). The chamfer width was measured at the central part of mesial, distal, buccal and lingual surfaces (Lava Design 5.50 CAD software 3M/ESPE). Preparation and measurement were repeated until the defined chamfer width with an error range of $50 \mu \mathrm{m}$ or less was obtained. The occlusal surface was prepared to be V-shape to ensure as equal thickness as possible for the occlusal ceramic (Fig. 1b). The prepared and the non-prepared tooth models were scanned to evaluate the reduction of occlusal surface using the CAD software. The vertical distance was defined as the 
occlusal reduction and measurements were performed at 10 different points (Fig. 1c). The minimal reduction of occlusal surface was defined to be $0.6,1.1$ and $1.6 \mathrm{~mm}$ resulting in a minimal occlusal thickness of the crowns about $0.5,1.0$ and $1.5 \mathrm{~mm}$ including the cement space $(70 \mu \mathrm{m})$. Nine abutments were prepared and coded as follows; C0.5/O0.5, C0.5/O1.0, C0.5/O1.5, C0.7/O0.5, C0.7/O1.0, C0.7/O1.5, C1.0/O0.5, C1.0/O1.0 and C1.0/O1.5 (Fig. 2a-c). The first 2 digits express the chamfer width and the last 2 the minimal occlusal thickness. In addition, an abutment with facetted occlusal shape (chamfer width of $0.5 \mathrm{~mm} /$ occlusal reduction of $0.6 \mathrm{~mm}$ ) was prepared (C0.5/O0.5f, Fig. 2d). All abutments were scanned and dies were milled from composite resin blocks (Lava Ultimate, 3M/ESPE) using the CAD/CAM system performed at the 3M Education Center (Tokyo, Japan).

The flexural strength and modulus of elasticity of the die material were measured according to ISO 10477: 2004, "Dentistry-Polymer-based crown and bridge material (MOD)" [13] in a universal testing machine (AI-GS, Shimadzu, Kyoto, Japan). The Poisson's ratio was evaluated in compression using a universal testing machine with video extensiometer (Zwick/Roell, Ulm, Germany).

\section{Fabrication of crowns}

The dies were scanned, and crowns were designed by double scan technique in which additional scanning of the non-prepared tooth model was performed to obtain an identical outer shape for each type of dies. Then, 60 monolithic zirconia crowns ( 6 crowns for each type of die, Table 1) were milled from pre-sintered zirconia blocks (Lava Plus Zirconia, 3M/ESPE). Sample size was calculated based on the detection of a 
difference in mean fracture load of $1000 \mathrm{~N}$ between two groups with different crown thicknesses, assuming that $\mathrm{SD}$ was $500 \mathrm{~N}, \alpha=0.05$ and $\beta=0.02$. Coloring was performed using zirconia dyeing liquid (A2, Lava 3M/ESPE) followed by final sintering. The fabrication process was performed at the Lava Milling Center (Dental Digital Operation, Osaka, Japan). After sintering, margin adjustment was performed manually using a dental micromotor (Ultimate 500, Nakanishi, Tochigi, Japan) and grinding point (CeraPro, Edenta, AU/SG, Switzerland). Polishing was done using polishing points (StarGloss, Edenta) and wheel brush together with polishing agent (Zircon-Brite, Dental Ventures of America, Corona, CA, USA).

Six monolithic lithium disilicate crowns (IPS e.max press, Ivoclar/Vivadent, Schaan, Liechtenstein) were fabricated on the C1.0/O1.5 die (C1.0/O1.5e.max press, Table 1). A mold of the non-prepared tooth was produced using a silicone impression material (Exafine, GC, Tokyo, Japan). A spacer $(\mathrm{Th}=70 \mu \mathrm{m})$ and a separator were applied onto the die surfaces. The mold was fit to the die and molten wax was poured into the mold to obtain the identical outer shape of the non-prepared tooth, i.e. also identical to the monolithic zirconia crowns. Subsequent investment, pressing and glazing were performed according to the manufacturer's instructions.

\section{Evaluation of thickness}

The thicknesses of all specimens (i.e. six crowns for each type) were evaluated with micro-CT (ScanXmate-D225RSS270, Comscantecno, Kanagawa, Japan) using the following measurement conditions: voltage; $200 \mathrm{kV}$ (zirconia) vs. $90 \mathrm{kV}$ (lithium disilicate), current; $200 \mu \mathrm{A}$ (zirconia) vs. $220 \mu \mathrm{A}$ (lithium disilicate), resolution (voxel 
size) $14.9 \mu \mathrm{m}$. ImageJ (The Research Services Branch of the NIH), an image processing program, was used for analysis. The thickness was measured at the same points as those used for the evaluation of the abutments (Fig. 1).

\section{Cementation}

Each crown was luted onto their respective die using a resin-based cement (Panavia F2.0, Kuraray Noritake Dental, Tokyo, Japan) according to the manufacturer's instructions. A static load of $20 \mathrm{~N}$ was applied using a universal testing machine (AI-GS) [14]. Excess was removed immediately after loading and Oxyguard (Kuraray Noritake Dental) was applied around the margin. The crown-die samples were stored in distilled water at $37 \pm 1^{\circ} \mathrm{C}$ for $24 \pm 1 \mathrm{~h}$ before load-to-failure test.

\section{Load-to-failure test}

The test was performed in a universal testing machine (AI-GS) with a $10 \mathrm{kN}$ load cell. A custom-made semi-spherical indenter $(\varnothing=10 \mathrm{~mm})$ of type 304-stainless steel (Kabumoto, Osaki, Japan) was placed in the central fossa of the occlusal surface. Great caution was taken to place the indenter identical at each test occasion. A urethane rubber sheet (Kokugo, Tokyo, Japan) $(\mathrm{Th}=2 \mathrm{~mm}$, Shore A Hardness=90) was interspersed between the indenter and the occlusal surface to avoid contact damage [15]. A preload of $20 \mathrm{~N}$ was applied vertically to the crown followed by compressive loading at a crosshead-speed of $0.5 \mathrm{~mm} / \mathrm{min}$ until fracture.

\section{Statistics}


Statistical analyses were performed using JMP Pro 11.0.0 software (SAS Institute, Cary NC, USA). Differences in axial/occlusal thickness and fracture load were analyzed using Tukey-Kramer HSD multiple comparison test. When the crowns did not fracture within $10 \mathrm{kN}$ (the limit of the load-cell) the value of $10 \mathrm{kN}$ was used. The influence of the axial and occlusal thickness was assessed by multiple regression analysis. The representative thickness of the axial wall and occlusal surface for each crown, calculated as an average of 4 measuring points and as an average of minimal thickness at the measuring points of B, F and I (Fig. 1c), respectively, were used for the multiple regression analysis. The level of significance was set at 5\%.

\section{Results}

\section{Evaluation of die material and crowns}

The flexural strength, the E-modulus, and the Poisson's ratio of the die material were $196 \pm 10 \mathrm{MPa}, 10.73 \pm 0.28 \mathrm{GPa}$, and $0.43 \pm 0.03$, respectively. The axial and occlusal thickness of the crowns are summarized in Table 2. There were significant differences in axial/occlusal thickness between the different groups at any measurement points ( $\mathrm{p}<0.01)$. In $\mathrm{C} 0.5 / \mathrm{O} 0.5 \mathrm{f}$, the occlusal thickness was $0.5 \pm 0.1 \mathrm{~mm}$ at any measurement points (Table 2). Furthermore, it was observed that the zirconia crowns had no internal defects while lithium disilicate crowns showed voids inside the crowns.

\section{Load-to-failure test}

One out of 6,4 of 6 , and 4 of 6 crowns from the group of C0.5/O1.5, C0.7/O1.5, and C1.0/O1.5, respectively, did not fracture even at $10 \mathrm{kN}$. As shown in Fig. 3, there were 
significant differences $(\mathrm{p}<0.05)$ in the fracture load between the crowns of various thickness. Based on the measurement of crown thickness and the fracture load, multiple regression analysis was performed, and the following statistical prediction formula was calculated.

That is, $\mathrm{F}=3295+657 \times \mathrm{A}+3465 \times \mathrm{O}$

where $\mathrm{F}$ is the fracture load $(\mathrm{N}), \mathrm{A}$ is the axial thickness $(\mathrm{mm})$, and $\mathrm{O}$ is the occlusal thickness (mm).

Adjusted coefficient of determination was 0.711 . It was revealed that the occlusal thickness significantly affected the fracture load $(\mathrm{p}<0.01)$ whereas the axial thickness $\operatorname{did} \operatorname{not}(\mathrm{p}=0.2828)$.

Although the reduction of occlusal thickness decreased the fracture resistance of monolithic zirconia crown, the fracture load of $\mathrm{C} 0.5 / \mathrm{O} 0.5(5558 \pm 522 \mathrm{~N})$ and $\mathrm{C} 0.5 / \mathrm{O} 0.5 \mathrm{f}(4597 \pm 532 \mathrm{~N})$ was significantly higher than that of $\mathrm{C} 1.0 / \mathrm{O} 1.5 \mathrm{e} . \mathrm{max}$ press $(3147 \pm 409$ N) (Fig. 4). Between the two types of monolithic zirconia crowns (V-shape and facetted shape), $\mathrm{C} 0.5 / \mathrm{O} 0.5 \mathrm{f}$ showed significantly lower fracture load than $\mathrm{C} 0.5 / \mathrm{O} 0.5$.

\section{Discussion}

In the present study, the preparation of materials and load-to-failure test were performed basically according to the recommendation for clinically relevant preclinical tests [16]. It was demonstrated that the strength of the monolithic zirconia crowns tested was dependent on the occlusal thickness. Furthermore, under the condition used in the present study, the monolithic zirconia crowns tested showed higher fracture resistance 
than monolithic lithium disilicate crowns. The results suggest that monolithic zirconia crown with reduced thickness can be applied to molar region. Therefore, the hypothesis was accepted.

Flexural strength as well as E-modulus and Poisson's ratio of die materials has been considered important for the fracture resistance of all-ceramic crowns [17-19]. It has been suggested that a low E-modulus of the die material (10-14 GPa) as compared to ceramics $(70-220 \mathrm{GPa})$ may be more accurate in terms of deformation since it will closer match the value of human dentin. In the present study, the elastic properties were in the range of those reported in earlier studies on resin-based polymer materials [17, 18]. The Poisson's ratio of the die material in use (0.43) was found to be close to that of wet (i.e. vital) dentin $(0.38-0.45)$ [20, 21]. It should be remembered though that the determination of the Poisson value is liable to variations due to different dentin conditions (dry-wet) and strain rates. In theory a high Poisson's ratio may result in crack formation close to the crown margins due to compression-induced expansion of the die material. That was not seen in the present study. A logic conclusion must be that the monolithic zirconia used was able to withstand the developed stress without fracturing.

There were significant differences in the axial and the occlusal thickness between the different groups according to the micro-CT analysis. Since other parameters, such as the crown shape and the height of the axial wall, which is known to influence the fracture resistance of posterior all-ceramic crowns [22], were standardized, it is considered that the difference in fracture load for each type of the monolithic zirconia crowns were related to the crown thickness. Another finding from the micro-CT analysis was that pressed lithium disilicate crowns contained several voids 
while the CAD/CAM made zirconia crowns did not.

In the load-to-failure test, some of the monolithic zirconia crowns with occlusal thickness of $1.5 \mathrm{~mm}$ were not fractured even at $10 \mathrm{kN}$. This results is consistent with a previous report wherein Beuer et al. (2012) [23] demonstrated that 11 out of 12 monolithic zirconia crowns did not fail at $10.5 \mathrm{kN}$. Their dies imitating tooth 46 with $1.2 \mathrm{~mm}$ chamfer preparation and $1.5 \mathrm{~mm}$ occlusal reduction seemed comparable to C1.0/O1.5 dies used in the present study.

Based on the multiple regression analysis, the occlusal thickness significantly affected the fracture resistance. It is known that the occlusal thickness of all-ceramic crowns is one of the primary factors influencing stress and fracture resistance [24, 25]. For the monolithic zirconia crowns tested in the present study, an increase in occlusal thickness with $1 \mathrm{~mm}$ resulted in an augmented fracture load with $3465 \mathrm{~N}$ according to the multiple regression analysis. Therefore, even for patients with high loading forces, only a small increase in occlusal thickness of a monolithic zirconia crown will probably contribute to sufficient increase in fracture resistance.

Contrary to the occlusal thickness, the axial thickness of monolithic zirconia crown did not significantly affect the fracture resistance. This finding is in accordance with previous studies on leucite-reinforced glass-ceramic crowns [26, 27]. However, when a load is applied at a different angle to the tooth axis, the axial thickness might affect the fracture resistance. It was demonstrated that lithium disilicate crowns with a wall thickness of $0.5 \mathrm{~mm}$ showed significantly lower fracture resistance than those with wall thicknesses of 1.0 and $1.5 \mathrm{~mm}$ when loaded with a tilt of $30^{\circ}$ to the tooth axis [28]. Although further studies are needed to reach conclusion, based on the present study it 
might be recommended that the axial wall should be prepared with slight chamfer (e.g. $0.5 \mathrm{~mm}$ ) when monolithic zirconia is used for crowns.

A recent systematic review found high survival rate for lithium disilicate single crowns (the 5-year cumulative survival rate: 97.8\%) [29]. In addition, since IPS e.max could be used in a monolithic form as in the case of monolithic zirconia crowns, they were used as a control in the present study. Two types of production technique for lithium disilicate restorations are commercially available, one for press technique and the other for CAD/CAM (e.g. IPS e.max press and IPS e.max CAD). Since IPS e.max press possesses higher flexural strength $(400 \pm 40 \mathrm{MPa})$ than IPS e.max CAD $(360 \pm 60$ $\mathrm{MPa}$ ) according to the manufacturer's data $[30,31]$, the former was used in the present study. Johansson et al. (2014) compared fracture resistance of monolithic zirconia and monolithic lithium disilicate (IPS e.max press) after thermo-cycling and cyclic loading. They reported higher strength for the zirconia crowns compared to lithium disilicate crowns with the same occlusal thickness $(\geq 1.8 \mathrm{~mm})$. In the present study, although the crowns were not subjected to thermo-cycling and cyclic loading, the fracture load of the monolithic zirconia crowns with an occlusal thickness of $0.5 \mathrm{~mm}$ were significantly higher versus the lithium disilicate crowns with an occlusal thickness of $1.5 \mathrm{~mm}$. These findings indicate that monolithic zirconia crowns can withstand the forces in molar region even with a minimal thickness of $0.5 \mathrm{~mm}$. Since zirconia has higher flexural strength $(1000 \mathrm{MPa})$ than lithium disilicate (400 MPa) [9-12], it is logic to assume that monolithic zirconia crowns with reduced thickness can show higher fracture resistance than monolithic lithium disilicate crowns with regular thickness. Limiting the occlusal reduction of the abutment preparation would probably contribute not only to the 
preservation of sound tooth substance but also to ensure adequate height of the axial walls of the abutment tooth, promoting retention and resistance of the crown. The result obtained that the fracture resistance of $\mathrm{C} 0.5 / \mathrm{O} 0.5 \mathrm{f}$ crowns was significantly lower than that of $\mathrm{C} 0.5 / \mathrm{O} 0.5$ crowns may suggest that several stress points were generated during load due to the shape of the surface with ridges. This would imply that the facetted design is not the most ideal preparation design for the ceramic crown.

In the present study, the load-to-failure test was performed without any aging procedures, such as cyclic loading, thermal cycling, thermo-mechanical cycling and autoclave-induced low temperature degradation (LTD). It has been demonstrated that flexural strength of zirconia decreases when subjected to such aging treatments $[32,33]$. With respect to dental zirconia prostheses, Kohorst et al. [34] demonstrated that cyclic loading with $1 \times 10^{6}$ cycles at $100 \mathrm{~N}$ together with $1 \times 10^{4}$ thermal cycles between 5 and $55^{\circ} \mathrm{C}$ significantly decreased the fracture resistance of zirconia-based FDPs. Since the stress distributions under cyclic loading for FDPs and crowns are completely different, the influence of such aging procedures on monolithic zirconia crown should be further studied. From a mechanical perspective accounting that a $20-40 \%$ reduction in fracture load might occur as a result of thermo-stressed cyclic loading in a wet environment [34] and possible effects of LTD [35], there still seems to be a considerable strength safety margin for monolithic zirconia crowns, even in situations of high biting forces. Within the limitations of the present study, it is suggested that monolithic zirconia crown with chamfer width of $0.5 \mathrm{~mm} /$ occlusal thickness of $0.5 \mathrm{~mm}$ can be used in the molar region in terms of fracture resistance. 


\section{Acknowledgement}

The authors would like to acknowledge 3M/ESPE for generously supplying the die materials. This research was supported by JSPS KAKENHI, Grant-in-Aid for Scientific Research (C), 25462981, 2013.

\section{Declaration of interest}

The authors declare no potential conflicts of interest with respect to the research, authorship, and/or publication of this article. 


\section{References:}

[1] Denry I, Kelly JR. State of the art of zirconia for dental applications. Dent Mater 2008;24:299-307.

[2] Garvie R, Hannink CRH, Pascoe R T. Ceramic steel? Nature 1975;258:703-4.

[3] Ortorp A, Kihl ML, Carlsson GE. A 3-year retrospective and clinical follow-up study of zirconia single crowns performed in a private practice. J Dent 2009;37:731-6. [4] Al-Amleh B, Lyons K, Swain M. Clinical trials in zirconia: A systematic review. J Oral Rehabil 2010;37:641-52.

[5] Johansson C, Kmet G, Rivera J, Larsson C, Vult Von Steyern P. Fracture strength of monolithic all-ceramic crowns made of high translucent yttrium oxide-stabilized zirconium dioxide compared to porcelain-veneered crowns and lithium disilicate crowns. Acta Odontol Scand 2014;72:145-53.

[6] Stober T, Bermejo JL, Rammelsberg P, Schmitter M. Enamel wear caused by monolithic zirconia crowns after 6 months of clinical use. J Oral Rehabil 2014;41:314-22.

[7] Milleding P. Preparation design for traditional fixed full-crown restorations. Preparations for fixed prosthodontics. Denmark: Munksgaard; 2012. p. 155-63.

[8] Dhima M, Carr AB, Salinas TJ, Lohse C, Berglund L, Nan KA. Evaluation of fracture resistance in aqueous environment under dynamic loading of lithium disilicate restorative systems for posterior applications. Part 2. J Prosthodont 2014;23:353-7

[9] Piconi C, Maccauro G. Zirconia as a ceramic biomaterial. Biomaterials 1999;20:1-25.

[10] Nakamura K, Adlfsson E, Milleding P, Kanno T, Ortengren U. Influence of 
grain size and veneer firing process on flexural strength of zirconia ceramics. Eur J Oral Sci 2012;120:249-54.

[11] Holand W, Schweiger M, Frank M, Rheinberger V. A comparison of the microstructure and properties of the IPS Empress 2 and the IPS Empress glass-ceramics. J Biomed Mater Res 2000;53:297-303.

[12] Kang SH, Chang J, Son HH. Flexural strength and microstructure of two lithium disilicate glass ceramics for $\mathrm{CAD} / \mathrm{CAM}$ restoration in the dental clinic. Restor Dent Endod 2013;38:134-40.

[13] ISO10477. Dentistry - Polymer-based crown and bridge materials. Switzerland: ISO Geneva; 2004.

[14] Pallis K, Griggs JA, Woody RD, Guillen GE, Miller AW. Fracture resistance of three all-ceramic restorative systems for posterior applications. J Prosthet Dent 2004;91:561-9.

[15] Oilo M, Kvam K, Tibballs JE, Gjerdet NR. Clinically relevant fracture testing of all-ceramic crowns. Dent Mater 2013;29:815-23.

[16] Kelly JR. Clinically relevant approach to failure testing of all-ceramic restorations. J Prosthet Dent 1999;81:652-61.

[17] Scherrer SS, de Rijk WG. The fracture resistance of all-ceramic crowns on supporting structures with different elastic moduli. Int J Prosthodont 1993;6:462-7. [18] Yucel MT, Yondem I, Aykent F, Eraslan O. Influence of the supporting die structures on the fracture strength of all-ceramic materials. Clin Oral Investig 2012;16:1105-10.

[19] Kelly JR, Tesk JA, Sorensen JA. Failure of all-ceramic fixed partial dentures in 
vitro and in vivo: analysis and modeling. J Dent Res 1995;74:1253-8.

[20] Kinney JH, Gladden JR, Marshall GW, Marshall SJ, So JH, Maynard JD.

Resonant ultrasound spectroscopy measurements of the elastic constants of human dentin. J Biomech 2004;37:437-41.

[21] Kinney JH, Marshall SJ, Marshall GW. The mechanical properties of human dentin: a critical review and re-evaluation of the dental literature. Crit Rev Oral Biol Med 2003;14:13-29.

[22] Scherrer SS, de Rijk WG. The effect of crown length on the fracture resistance of posterior porcelain and glass-ceramic crowns. Int J Prosthodont 1992;5:550-7. [23] Beuer F, Stimmelmayr M, Gueth JF, Edelhoff D, Naumann M. In vitro performance of full-contour zirconia single crowns. Dent Mater 2012;28:449-56. [24] Rekow ED, Harsono M, Janal M, Thompson VP, Zhang G. Factorial analysis of variables influencing stress in all-ceramic crowns. Dent Mater 2006;22:125-32. [25] Wolf D, Bindl A, Schmidlin PR, Luthy H, Mormann WH. Strength of CAD/CAM-generated esthetic ceramic molar implant crowns. Int J Oral Maxillofac Implants 2008;23:609-17.

[26] Skouridou N, Pollington S, Rosentritt M, Tsitrou E. Fracture strength of minimally prepared all-ceramic CEREC crowns after simulating 5 years of service. Dent Mater 2013;29:e70-7.

[27] Tsitrou EA, Helvatjoglu-Antoniades M, van Noort R. A preliminary evaluation of the structural integrity and fracture mode of minimally prepared resin bonded CAD/CAM crowns. J Dent 2010;38:16-22.

[28] Seydler B, Rues S, Muller D, Schmitter M. In vitro fracture load of monolithic 
lithium disilicate ceramic molar crowns with different wall thicknesses. Clin Oral Investig 2013; 18:1165-71

[29] Pieger S, Salman A, Bidra AS. Clinical outcomes of lithium disilicate single crowns and partial fixed dental prostheses: a systematic review. J Prosthet Dent 2014;112:22-30.

[30] Ivoclar/Vivadent. Scientific documentation: IPS e.max Press. [cited 2014 Oct 27]. Available from:

http://www.ivoclarvivadent.us/en-us/download-center/scientific-documentation/ [31] Ivoclar/Vivadent. Scientific documentation: IPS e.max CAD. [cited 2014 Oct 27]. Available from:

http://www.ivoclarvivadent.us/en-us/download-center/scientific-documentation/ [32] Cotes C, Arata A, Melo RM, Bottino MA, Machado JP, Souza RO. Effects of aging procedures on the topographic surface, structural stability, and mechanical strength of a ZrO-based dental ceramic. Dent Mater 2014. Epub ahead of print [33] Flinn B, deGroot D, Mancl L, Raigrodski AJ. Accelerated aging characteristics of three yttria-stabilized tetragonal zirconia polycrystalline dental materials. J Prosthet Dent 2012;108:223-30.

[34] Kohorst P, Dittmer MP, Borchers L, Stiesch-Scholz M. Influence of cyclic fatigue in water on the load-bearing capacity of dental bridges made of zirconia. Acta Biomater 2008;4:1440-7.

[35] Chevalier J, Gremillard L, Deville S. Low-temperature degradation of zirconia and implications for biomedical implants. Ann Rev Mater Res 2007;37:1-32. 
Tables:

Table 1. The groups of monolithic crowns tested

\begin{tabular}{lcc}
\hline Group & $\begin{array}{c}\text { Chamfer } \\
\text { width } \\
(\mathrm{mm})\end{array}$ & $\begin{array}{c}\text { Minimal occlusal } \\
\text { thickness } \\
(\mathrm{mm})\end{array}$ \\
\hline $\mathrm{C} 0.5 / \mathrm{O} 0.5$ & 0.5 & 0.5 \\
$\mathrm{C} 0.5 / 01.0$ & 0.5 & 1.0 \\
$\mathrm{C} 0.5 / \mathrm{O} 1.5$ & 0.5 & 1.5 \\
$\mathrm{C} 0.7 / \mathrm{O} 0.5$ & 0.7 & 0.5 \\
$\mathrm{C} 0.7 / 01.0$ & 0.7 & 1.0 \\
$\mathrm{C} 0.7 / \mathrm{O} 1.5$ & 0.7 & 1.5 \\
$\mathrm{C} 1.0 / \mathrm{O} 0.5$ & 1.0 & 0.5 \\
$\mathrm{C} 1.0 / 01.0$ & 1.0 & 1.0 \\
C1.0/O1.5 & 1.0 & 1.5 \\
C0.5/O0.5f* & 0.5 & 0.5 \\
C1.0/O1.55e.max press & 1.0 & 1.5 \\
\hline
\end{tabular}

*: $\mathrm{C} 0.5 / \mathrm{O} 0.5 \mathrm{f}$ was fabricated on the die with the facetted occlusal surface. 
Table 2. Axial and occlusal thickness of crowns evaluated by micro-CT analysis. Each value represents the mean of sextuplicate measurements with standard deviation given within the parentheses.

\begin{tabular}{|c|c|c|c|c|c|c|c|c|c|c|c|c|c|c|}
\hline & \multicolumn{4}{|c|}{ Axial thickness (mm) } & \multicolumn{10}{|c|}{ Occlusal thickness (mm) } \\
\hline $\mathrm{C} 0.5 / 00.5$ & $\begin{array}{c}0.84 \\
(0.02)\end{array}$ & $\begin{array}{c}0.71 \\
(0.02)\end{array}$ & $\begin{array}{c}0.75 \\
(0.02)\end{array}$ & $\begin{array}{c}0.70 \\
(0.01)\end{array}$ & $\begin{array}{c}1.00 \\
(0.01)\end{array}$ & $\begin{array}{c}0.50 \\
(0.01)\end{array}$ & $\begin{array}{c}1.03 \\
(0.02)\end{array}$ & $\begin{array}{c}0.64 \\
(0.02)\end{array}$ & $\begin{array}{c}0.62 \\
(0.03)\end{array}$ & $\begin{array}{c}0.50 \\
(0.01)\end{array}$ & $\begin{array}{c}0.64 \\
(0.01)\end{array}$ & $\begin{array}{c}1.08 \\
(0.01)\end{array}$ & $\begin{array}{c}0.57 \\
(0.01)\end{array}$ & $\begin{array}{r}1.03 \\
(0.02)\end{array}$ \\
\hline $\mathrm{C} 0.5 / \mathrm{O} 1.0$ & $\begin{array}{c}0.81 \\
(0.02)\end{array}$ & $\begin{array}{c}0.72 \\
(0.02)\end{array}$ & $\begin{array}{c}0.79 \\
(0.02)\end{array}$ & $\begin{array}{c}0.72 \\
(0.02)\end{array}$ & $\begin{array}{c}1.44 \\
(0.01)\end{array}$ & $\begin{array}{c}1.05 \\
(0.01)\end{array}$ & $\begin{array}{c}1.50 \\
(0.02)\end{array}$ & $\begin{array}{c}1.14 \\
(0.01)\end{array}$ & $\begin{array}{c}1.08 \\
(0.01)\end{array}$ & $\begin{array}{c}1.06 \\
(0.01)\end{array}$ & $\begin{array}{c}1.23 \\
(0.01)\end{array}$ & $\begin{array}{c}1.47 \\
(0.01)\end{array}$ & $\begin{array}{c}1.07 \\
(0.01)\end{array}$ & $\begin{array}{r}1.56 \\
(0.01)\end{array}$ \\
\hline $\mathrm{C} 0.5 / \mathrm{O} 1.5$ & $\begin{array}{c}0.78 \\
(0.02)\end{array}$ & $\begin{array}{c}0.72 \\
(0.01)\end{array}$ & $\begin{array}{c}0.78 \\
(0.03)\end{array}$ & $\begin{array}{c}0.69 \\
(0.02)\end{array}$ & $\begin{array}{c}1.96 \\
(0.01)\end{array}$ & $\begin{array}{c}1.45 \\
(0.02)\end{array}$ & $\begin{array}{c}1.97 \\
(0.01)\end{array}$ & $\begin{array}{c}1.53 \\
(0.03)\end{array}$ & $\begin{array}{c}1.64 \\
(0.01)\end{array}$ & $\begin{array}{c}1.52 \\
(0.02)\end{array}$ & $\begin{array}{c}1.67 \\
(2.02)\end{array}$ & $\begin{array}{c}2.02 \\
(0.02)\end{array}$ & $\begin{array}{c}1.49 \\
(0.02)\end{array}$ & $\begin{array}{r}2.00 \\
(0.03)\end{array}$ \\
\hline C0.7/O1.0 & $\begin{array}{c}1.13 \\
(0.03)\end{array}$ & $\begin{array}{c}0.90 \\
(0.02)\end{array}$ & $\begin{array}{c}0.94 \\
(0.04)\end{array}$ & $\begin{array}{c}0.94 \\
(0.02)\end{array}$ & $\begin{array}{c}1.49 \\
(0.01)\end{array}$ & $\begin{array}{c}0.99 \\
(0.01)\end{array}$ & $\begin{array}{c}1.57 \\
(0.01)\end{array}$ & $\begin{array}{c}1.17 \\
(0.02)\end{array}$ & $\begin{array}{c}1.07 \\
(0.01)\end{array}$ & $\begin{array}{c}1.11 \\
(0.02)\end{array}$ & $\begin{array}{c}1.26 \\
(0.02)\end{array}$ & $\begin{array}{c}1.66 \\
(0.01)\end{array}$ & $\begin{array}{c}1.11 \\
(0.01)\end{array}$ & $\begin{array}{r}1.66 \\
(0.01)\end{array}$ \\
\hline $\mathrm{C} 0.7 / \mathrm{O} 1.5$ & $\begin{array}{c}1.04 \\
(0.02)\end{array}$ & $\begin{array}{c}0.93 \\
(0.02)\end{array}$ & $\begin{array}{c}1.00 \\
(0.02)\end{array}$ & $\begin{array}{c}0.94 \\
(0.01)\end{array}$ & $\begin{array}{c}1.94 \\
(0.01)\end{array}$ & $\begin{array}{c}1.43 \\
(0.02)\end{array}$ & $\begin{array}{c}2.01 \\
(0.02)\end{array}$ & $\begin{array}{r}1.56 \\
(0.02)\end{array}$ & $\begin{array}{c}1.72 \\
(0.02)\end{array}$ & $\begin{array}{c}1.51 \\
(0.02)\end{array}$ & $\begin{array}{c}1.60 \\
(0.02)\end{array}$ & $\begin{array}{c}2.18 \\
(0.03)\end{array}$ & $\begin{array}{c}1.59 \\
(0.02)\end{array}$ & $\begin{array}{r}2.05 \\
(0.02)\end{array}$ \\
\hline C1.0/O0.5 & $\begin{array}{c}1.33 \\
(0.02)\end{array}$ & $\begin{array}{c}1.22 \\
(0.02)\end{array}$ & $\begin{array}{c}1.23 \\
(0.03)\end{array}$ & $\begin{array}{c}1.12 \\
(0.02)\end{array}$ & $\begin{array}{c}1.16 \\
(0.02)\end{array}$ & $\begin{array}{c}0.55 \\
(0.01)\end{array}$ & $\begin{array}{c}1.03 \\
(0.02)\end{array}$ & $\begin{array}{c}0.72 \\
(0.02)\end{array}$ & $\begin{array}{c}0.84 \\
(0.02)\end{array}$ & $\begin{array}{c}0.56 \\
(0.01)\end{array}$ & $\begin{array}{c}0.67 \\
(0.01)\end{array}$ & $\begin{array}{c}1.41 \\
(0.02)\end{array}$ & $\begin{array}{c}0.65 \\
(0.01)\end{array}$ & $\begin{array}{r}1.24 \\
(0.01)\end{array}$ \\
\hline $\mathrm{C} 0.5 / 00.5 f$ & $\begin{array}{c}0.88 \\
(0.01)\end{array}$ & $\begin{array}{c}0.66 \\
(0.01)\end{array}$ & $\begin{array}{c}0.81 \\
(0.02)\end{array}$ & $\begin{array}{c}0.66 \\
(0.01)\end{array}$ & $\begin{array}{c}0.46 \\
(0.01)\end{array}$ & $\begin{array}{c}0.45 \\
(0.01)\end{array}$ & $\begin{array}{c}0.55 \\
(0.02)\end{array}$ & $\begin{array}{c}0.48 \\
(0.02)\end{array}$ & $\begin{array}{c}0.60 \\
(0.01)\end{array}$ & $\begin{array}{c}0.50 \\
(0.01)\end{array}$ & $\begin{array}{c}0.56 \\
(0.02)\end{array}$ & $\begin{array}{c}0.55 \\
(0.03)\end{array}$ & $\begin{array}{c}0.54 \\
(0.01)\end{array}$ & $\begin{array}{c}0.57 \\
(0.01)\end{array}$ \\
\hline $\begin{array}{l}\text { C1.0/01.5 } \\
\text { e.max press }\end{array}$ & $\begin{array}{r}1.30 \\
(0.05)\end{array}$ & $\begin{array}{l}1.30 \\
(0.04)\end{array}$ & $\begin{array}{r}1.39 \\
(0.06)\end{array}$ & $\begin{array}{r}1.33 \\
(0.05)\end{array}$ & $\begin{array}{l}2.51 \\
(0.16)\end{array}$ & $\begin{array}{r}1.55 \\
(0.14)\end{array}$ & $\begin{array}{l}1.96 \\
(0.13)\end{array}$ & $\begin{array}{r}1.70 \\
(0.11)\end{array}$ & $\begin{array}{r}1.70 \\
(0.18)\end{array}$ & $\begin{array}{r}1.48 \\
(0.13)\end{array}$ & $\begin{array}{c}1.57 \\
(0.18)\end{array}$ & $\begin{array}{l}2.32 \\
(0.16)\end{array}$ & $\begin{array}{r}1.69 \\
(0.13)\end{array}$ & $\begin{array}{l}2.18 \\
(0.15)\end{array}$ \\
\hline
\end{tabular}

m: mesial, d: distal, b: buccal, l: lingual, A-B correspond to those shown in Fig. 1c. 


\section{Figure captions}

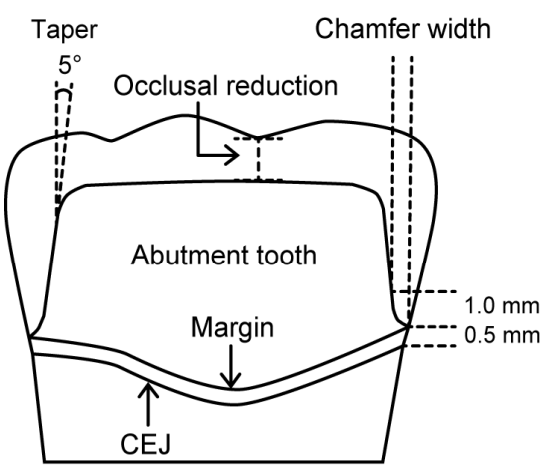

a. Buccal aspect

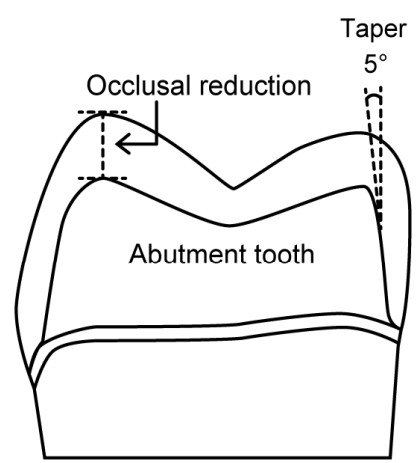

b. Mesial aspect

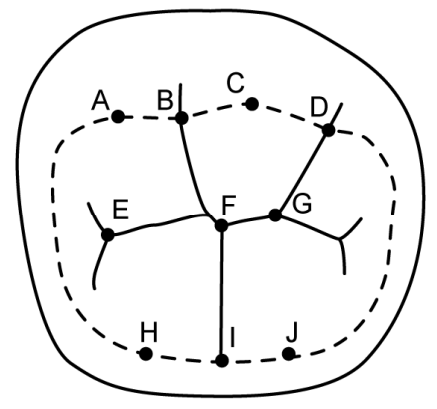

c. Occlusal aspect

Fig. 1 Schematic illustration of the abutment tooth $46(a, b)$ and measurement points for occlusal reduction (c). Chamfer width was defined as the distance between the axial wall and the vertical line from the edge of finishing line at $1 \mathrm{~mm}$ above the margin. Occlusal reduction was measured as the vertical distance between the prepared and the non-prepared tooth models at 10 different points (A-J). The minimal occlusal thickness was obtained at B, F and I. CEJ: cement enamel junction
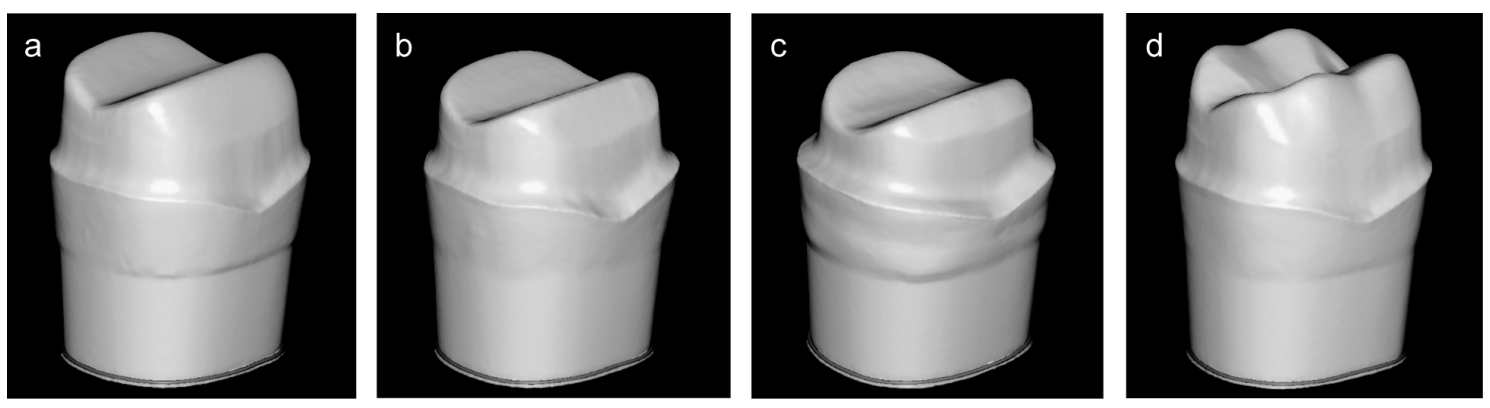

Fig. 2 Scanned abutment images of C0.5/O0.5 (a), C0.7/O1.0 (b), C1.0/O1.5 (c) and $\mathrm{C} 0.5 / \mathrm{O} 0.5 \mathrm{f}(\mathrm{d})$. 


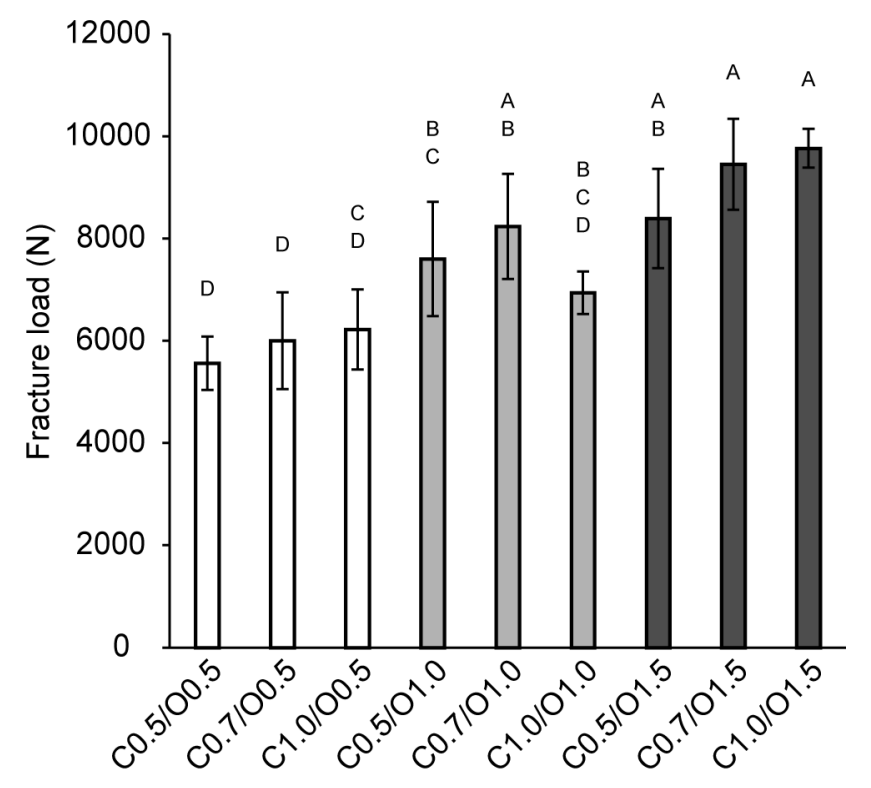

Fig. 3 Fracture load of the monolithic zirconia crowns tested. Each value represents the mean of six measurements with SD. Different letters above the columns show significant differences $(\mathrm{p}<0.01)$ except for the difference between $\mathrm{C} 0.7 / \mathrm{O} 0.5$ and $\mathrm{C} 0.5 / \mathrm{O} 1.0(\mathrm{p}<0.05)$

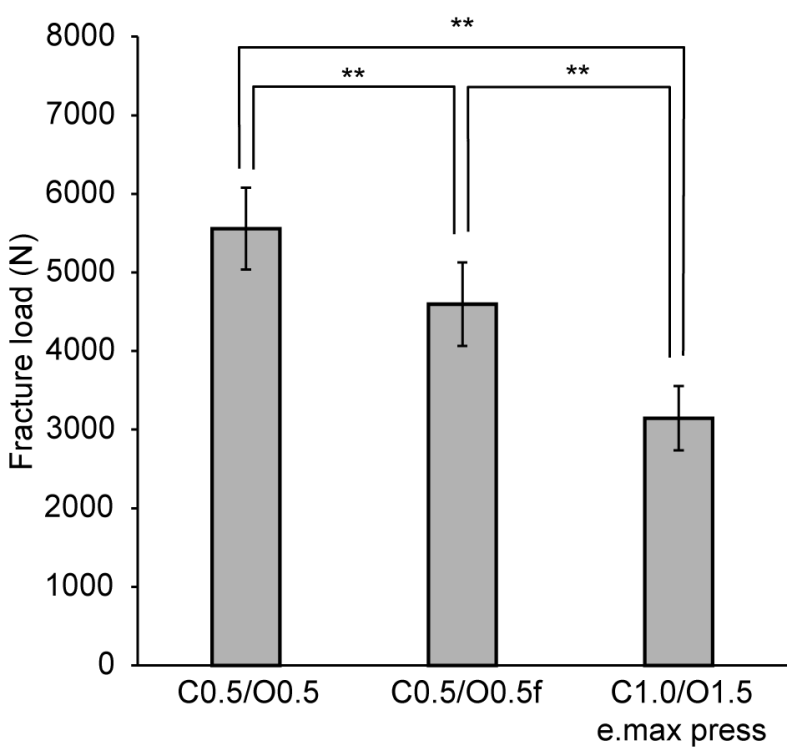

Fig. 4 Comparison of fracture load of monolithic zirconia crown with reduced thickness (C0.5/O0.5 and $\mathrm{C} 0.5 / \mathrm{O} 0.5 \mathrm{f})$ with that of lithium disilicate crown 
(C1.0/O1.5e.max press). Each value represents the mean of six measurements with SD. $* *: p<0.01$ 